\title{
ESTRATEGIA INTEGRADA PARA LA RECUPERACIÓN DE TRAMOS FLUVIALES URBANOS. EL CASO DEL RÍO PILES EN GIJÓN COMPATIBLE CON USOS DEPORTIVOS
}

\author{
Francisco Pellicer Corellano \\ Departamento de Geografía y Ordenación del Territorio, \\ Facultad de Filosofía y Letras, Universidad de Zaragoza, \\ C/ Pedro Cerbuna 12, 50009, Zaragoza \\ pellicer@unizar.es \\ Samuel Barrao Simorte \\ Departamento de Geografía y Ordenación del Territorio, \\ Facultad de Filosofía y Letras, Universidad de Zaragoza, \\ C/ Pedro Cerbuna 12, 50009, Zaragoza \\ sbarrao@unizar.es \\ Marcos López-Álvarez \\ Biólogo especialista en Calidad de Aguas, \\ Gijón, Asturias \\ marcosldl@gmail.com
}

\begin{abstract}
Resumen: La recuperación ambiental del río Piles a su paso por Gijón con la inclusión compatible de los usos deportivos náuticos, representa un importante desafío para la ciudad. El Ayuntamiento de Gijón ha elaborado un Plan de Acción que plantea la demolición de la represa que facilita la práctica deportiva en el anillo navegable. La decisión municipal ha desatado una fuerte oposición social que ve peligrar la práctica del piragüismo.

El conflicto está suscitando un interesante debate sobre la gestión siempre controvertida de los espacios fluviales en la ciudad. Los estudios científicos que avalan la decisión política del Ayuntamiento de Gijón, revisten un marcado carácter sectorial por lo que no acaban de ofrecer una visión integrada del problema en el que interactúan elementos y factores ambientales, sociales, económicos y culturales propios de la interfase urbano-fluvial.
\end{abstract}


En este contexto, el enfoque holístico de la Geografía con las aportaciones altamente especializadas de la Biología en un diálogo interdisciplinar, ofrece un marco conceptual y metodológico apropiado para la planificación estratégica integrada, y se alinea con las políticas avanzadas de la UE y España.

Palabras clave: Geografía, Planificación, Río Piles, Gijón.

\title{
Integrated strategy for the recovery of urban river sections. The case of the river piles in Gijón compatible with sporting uses
}

\begin{abstract}
The environmental recovery of the river Piles as it passes through Gijón, with the compatible inclusion of nautical sporting uses, represents an important challenge for the city. Gijón city council has drawn up an Action Plan that proposes the demolition of the dam that facilitates the practice of sports in the navigable ring. The municipal decision has unleashed strong social opposition led by the Real Grupo Cultural Covadonga (RGCC), which sees the practice of canoeing in danger.

The conflict is giving rise to an interesting debate on the always controversial management of river areas in the city. The scientific studies that support the political decision of the Gijón City Council have a markedly sectorial character and therefore do not offer an integrated vision of the problem in which environmental, social, economic and cultural elements and factors of the urban-river interface interact.

In this context, the holistic approach of Geography with the highly specialised contributions of Biology in an interdisciplinary dialogue, offers an appropriate conceptual and methodological framework for integrated strategic planning, and is aligned with the advanced policies of the EU and Spain.
\end{abstract}

Keywords: Geography, Planning, Piles river, Gijón.

\section{Estado de la cuestión y antecedentes}

El estado hidrobiológico e hidrogeomorfológico del río Piles en el tramo urbano de Gijón, tras décadas de agresiones ambientales y abandono, presenta episodios de alta contaminación en la zona intermareal desde el Anillo Navegable de Gijón hasta la desembocadura en la playa de San Lorenzo. Mientras, 150.000 habitantes equivalentes de Gijón Este vierten sus aguas residuales sin depurar al medio natural, por lo que la Unión Europea está sancionando al Estado Español por el incumplimiento de la Directiva 91/271, de aguas residuales urbanas de Gijón, entre otras ciudades. 
Para abordar la problemática del río Piles, el Ayuntamiento de Gijón desarrolla un Plan de Acción basado en informes técnicos de la Empresa Municipal de Aguas (EMA) y la Confederación Hidrográfica del Cantábrico (CHC) y de estudios contratados con la ingeniería UVANT (2019-2020). Posteriormente, el Ayuntamiento de Gijón ha recibido un informe elaborado por Ecologistas en Acción (2020) "Plan de naturalización y restauración ambiental del río Piles a su paso por la ciudad de Xixón (Asturies)”y los estudios encargados a la Universidad de Oviedo (2020) sobre el "Nivel de salubridad de las aguas continentales y litorales de Gijón” y la Universidad Politécnica de Madrid (2021) sobre "Diagnóstico ambiental y propuestas de actuación para la rehabilitación y/o renaturalización del curso bajo de los ríos Piles y Peña Francia en el concejo de Gijón (Asturias).

En sus conclusiones, los informes científicos encargados por el ayuntamiento apoyan y se suman a la decisión política inicial de suprimir de manera definitiva las compuertas que permiten embalsar el anillo navegable y realizar un proyecto de restauración y recuperación fluvial del tramo afectado por el anillo navegable y la zona urbana del río Piles y Peña Francia. Las razones que justifican estas acciones se basan se basan en criterios sanitarios (presunta presencia de cianobacterias tóxicas) e impacto negativo de la represa y muros del anillo navegable sobre las condiciones hidrogeomorfológicas.

Desde la sociedad civil, el Real Grupo Cultural Covadonga (RGCC) como entidad que representa a 40.000 socios quiere asumir su responsabilidad y cooperar con la administración pública en el proceso de recuperación del río Piles. El RGCC comparte la preocupación por la contaminación de las masas de agua que amenazan el desarrollo de las actividades deportivas y recreativas en anillo navegable y la playa de San Lorenzo y degradan el territorio fluvial en el tramo urbano de Gijón. La entidad se suma y apoya cuantas medidas sean necesarias para la recuperación y mejora de las aguas y el cauce del río Piles, pero a la vez subraya el valor social y deportivo del anillo navegable como equipamiento público de la ciudad y se opone a su cierre. Al efecto, el RGCC ha encargado estudios complementarios a los del ayuntamiento con el objeto de contribuir a la búsqueda de alternativas que hagan compatible la recuperación del curso fluvial y sus riberas con el disfrute de unas instalaciones deportivas saludables y sostenibles en un contexto plenamente urbano. El equipo Agua Derecho y Medio Ambiente de la Universidad de Zaragoza, que jugó un papel determinante y adquirió una gran experiencia en la recuperación de las riberas del Ebro (2008), ha elaborado un documento sobre medidas de conservación y gestión para el anillo navegable como una instalación deportiva saludable, atractiva y sostenible (2020). Al estudio de la Universidad de Zaragoza se han sumado aportaciones del RGCC elaboradas por Asunción Cámara (2021) sobre la compatibilidad de usos del anillo navegable del río Piles; por el equipo INDUROT (2021) de la Universidad de Oviedo que ha realizado una propuesta preliminar sobre algunos de los requisitos a aplicar para minimizar los impactos en la hidrodinámica fluvial que puedan derivarse de la instalación de un azud hinchable en la confluencia de los ríos Piles y Peña Francia, que permita el aprovechamiento deportivo temporal de una parte de ambos cauces; y finalmente el informe del especialista en cia- 
nobacterias, Marcos López (2021) que desarticula los argumentos científicos sobre los que se sustenta la decisión política del Ayuntamiento de Gijón de destruir el anillo navegable por motivos sanitarios.

\section{Marco conceptual y normativo}

"Los retos globales de todo tipo, sociales, medioambientales, culturales, económicos $y$ de salud... deben abordarse dentro de las ciudades y mediante estrategias de carácter integrado y holísticas”. Agenda Urbana Española, 2019.

La Agenda Urbana Española impulsada por el Ministerio de Transportes, Movilidad y Agenda Urbana marca el camino para conseguir pueblos y ciudades más humanos. Este párrafo de su Introducción refleja adecuadamente el marco estratégico en el que se analiza el Anillo Navegable de Gijón (ANG) en el presente y con vistas al futuro.

Por otra parte, Ministerio para la Transición Ecológica y Reto Demográfico define su función principal como la elaboración de propuestas y ejecución de las políticas del gobierno en materia de energía y medio ambiente "para la transición a un modelo productivo y social más ecológico". Es decir, se trata de iniciar un proceso de cambios en los sistemas productivos y de consumo para adecuar un modelo actual que no lo es a un modelo marcadamente ecológico. La transición ha de hacer compatible el mantenimiento de las actividades humanas ligadas al desarrollo económico y social (deportivas en el caso que nos ocupa) sin alterar o mejorando las condiciones ambientales, reduciendo las amenazas para la salud y la dinámica hidrobiológica. En este contexto, salvar el anillo navegable de Gijón en el espacio fluvial urbano del río Piles recuperado, representa conseguir una ciudad más humana y sostenible.

Otros documentos de referencia de este estudio son los siguientes.

- La Estrategia Europea de Biodiversidad (EEB) que diferencia claramente los distintos contextos, el urbano, rural y natural, y en consecuencia la necesidad de establecer tratamientos propios en cada caso. La EEB hace hincapié en la necesidad de hacer más ecológicas las ciudades e incrementar la biodiversidad en los espacios urbanos.

- La Directiva Marco Europea del Agua (DMA), que se establece un marco de actuación comunitario en el ámbito de la política de aguas y que tiene por objetivo la protección de las aguas y promover un uso sostenible que garantice la disponibilidad del recurso natural a largo plazo.

- El Pacto Verde Europeo (PVE), que tiene por objetivos la protección, el mantenimiento y la mejora del capital natural, la protección de la salud y el bienestar 
de los ciudadanos frente a los riesgos y efectos medioambientales, con la particularidad de que subraya la participación activa de la ciudadanía, esencial para que las políticas funcionen y sean aceptadas. El PVE establece un plan de acción para impulsar un uso eficiente de los recursos mediante el paso a una economía limpia y circular y restaurar la biodiversidad y reducir la contaminación.

\section{Condiciones de partida}

La cuenca del río Piles se inscribe en el término municipal de Gijón, solo una pequeña parte de la cabecera pertenece al municipio de Siero, situado al Sur de Gijón. La superficie total de la cuenca es de $72,6 \mathrm{Km}^{2}$. La superficie del municipio de Gijón es de 182,2 $\mathrm{Km}^{2}$. Esto representa que el 39, $85 \%$ de la superficie del municipio está drenada por el río Piles. En el presente estudio, interesa conocer la presión que ejerce el territorio sobre las vías de agua, teniendo en cuenta el carácter natural, urbano o rural del espacio que vierte hacia el río y sus afluentes. Los principales indicadores son la población y sus actividades, las infraestructuras hidráulicas y viarias, la ocupación del suelo (Figura 1) y la carga ganadera.

\subsection{La cuenca superior del río Piles}

La cuenca superior de los ríos Piles y Peña Francia mantiene un régimen hidrológico bastante natural, sin infraestructuras de regulación significativas. Las alteraciones del sistema natural de la escorrentía y de la calidad de las masas de agua obedecen a las actividades humanas de ocupación y uso del suelo. La cuenca superior se caracteriza por paisajes rurales con pequeños núcleos de población. Los bosques ocupan las laderas más abruptas de las montañas que configuran la divisoria de aguas de la cuenca. Donde el relieve es más suave, predominan los pastos y cultivos, salpicados de algunas industrias y de numerosos núcleos rurales de densidad baja a media, que aumentan en tamaño y densidad conforme están más próximos al núcleo urbano.

Para conocer de un modo riguroso y objetivo la ocupación del suelo de la cuenca del río Piles, se ha partido del SIOSE (Sistema de Información sobre Ocupación del Suelo de España), a escala de referencia 1:25.000, que integra la información del Principado y de la Administración General del Estado. La cartografía disponible es de 2014. Así, la cuenca superior del río Piles puede considerarse como un espacio rural con un hábitat disperso de densidad variable, dedicado a actividades agrícolas y ganaderas propias del sector primario (praderas y cultivos anuales), a las que cabe añadir algunas industrias y áreas comerciales. Los espacios más naturales corresponden a los bosques que ocupan los espacios más altos y de mayor pendiente. Tres parroquias destacan por su ma- 


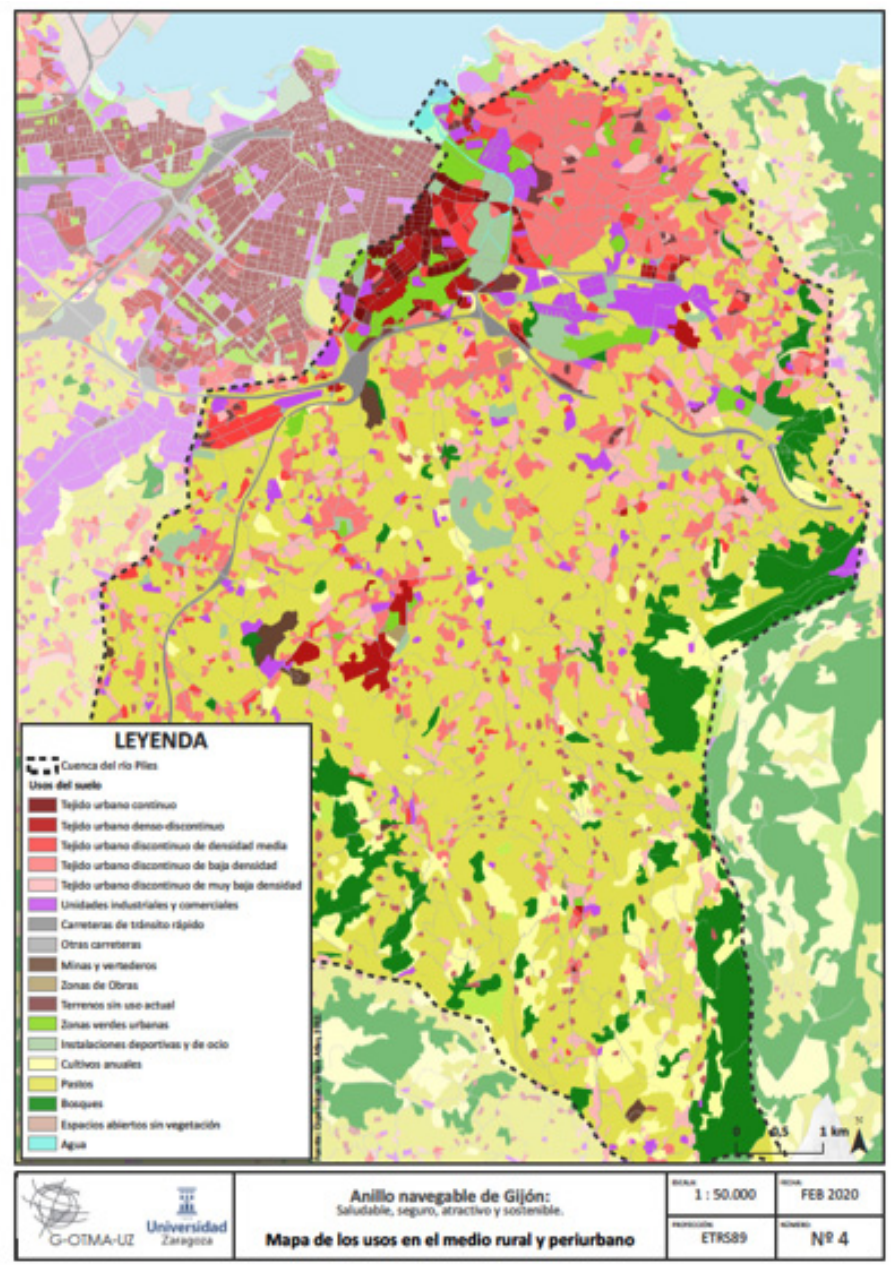

Figura 1. Mapa de usos del suelo de la cuenca del río Piles, Gijón.

Fuente: SIOSE (2014). Elaboración propia, proyecto Anillo Navegable de Gijón.

yor población y densidad: Vega, Castiello Bernueces y Cabueñes. En estas entidades se concentran preferentemente las actividades secundarias y terciarias que desempeñan y por la proximidad de Gijón. Funcionalmente cabe clasificarlas como ámbito periurbano.

Los principales ejes de la red viaria que teje el territorio se concentran en el sector septentrional más próximo a los centros urbanos y a la costa, alineados en sentido paralelo de Este a Oeste. Su disposición interrumpe los flujos naturales del agua que van de Sur a Norte o, si se prefiere, de la montaña al mar. Las autopistas y carreteras supo- 
nen un obstáculo que las aguas salvan a través de numerosos puentes sobre los cauces, pero frecuentemente las infraestructuras viarias interrumpen y modifican las escorrentías superficiales y ejercen un notable efecto de barrera frente a los flujos naturales. Para estimar la presión de las actividades del sector primario sobre la calidad de las masas de agua en cuenca del río Piles se han tomado datos del número de explotaciones y de las cabezas de la cabaña ganadera de Gijón y, cuando ha sido posible, se ha descendido a escala de las parroquias incluidas en la cuenca del río Piles.

Respecto a la ganadería, en el conjunto de Asturias, según las estadísticas oficiales, el número de cabezas de ganado vacuno se mantiene, pero baja el número de explotaciones. Ha bajado drásticamente el censo de ganado porcino, así como de gallinas y conejos. El ganado equino experimenta un crecimiento. De los datos precedentes se deduce que la cuenca superior del Piles recibe una carga contaminante difusa considerable, consecuencia de la presión demográfica, de la carga ganadera, de los usos del suelo y de las características del hábitat disperso. Como punto positivo se observa el descenso del sector porcino, gran productor de purines, que en otras regiones supone un grave impacto sobre el territorio.

Dadas las características geográficas de la cuenca superior del río Piles, para mantener la calidad de los cuerpos de agua que fluyen por el Piles y sus tributarios es preciso reforzar el conocimiento y control de los cuerpos de agua desde fuentes como núcleos residenciales dispersos, industrias, granjas y escorrentías de áreas agrícolas que drenan hacia los ríos. Sorprende la carencia de datos sobre caudales y calidad de las masas de agua.

\subsection{La cuenca inferior de la cuenca del Piles}

El tramo inferior de la cuenca ocupa una parte significativa de la ciudad de Gijón. La autopista A-8 puede servir como límite entre la ciudad y su ámbito periurbano y rural. Originalmente era un estuario rodeado de marismas escasamente valorado por la población que veía en él un obstáculo para las comunicaciones, un foco insalubre y, además, una oportunidad para la expansión de la ciudad. Así, en un período de aproximadamente un siglo, el río Piles se fue encauzando con grandes muros de hormigón y las marismas se desecaron y rellenaron con aportes de tierra para construir sobre ellas parques (Isabel la Católica), instalaciones deportivas (Estadio el Molinón, Palacio de los Deportes, Las Mestas, Covadonga) y otros equipamientos urbanos que requieren gran superficie (Feria). Carece también este tramo de infraestructuras de regulación. Solo una represa de compuertas móviles retiene una pequeña masa de agua, continuamente renovada, en el anillo navegable, que por su protagonismo en el tema que nos ocupa se trata con mayor detalle más adelante. 
A los efectos del presente estudio, conviene destacar tres aspectos fundamentales: las infraestructuras hidráulicas de saneamiento y drenaje (Figura 2), peligrosidad de inundación (Figura 3) y las afecciones del anillo navegable.

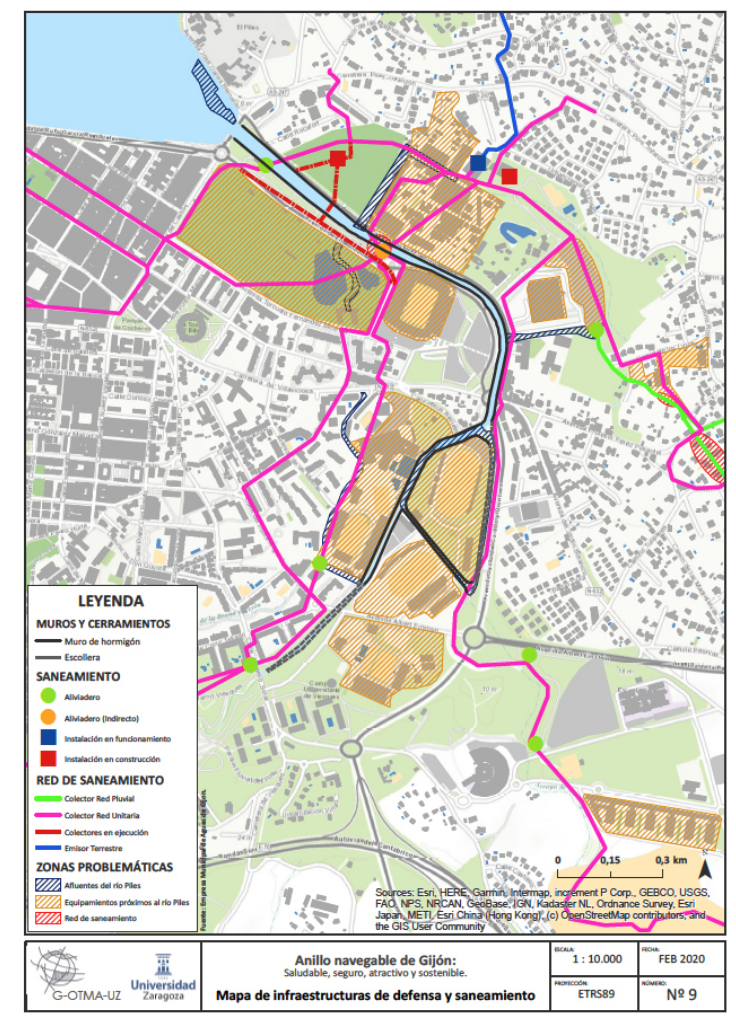

Figura 2. Mapa de infraestructuras urbanas de defensa y saneamiento de la red fluvial de Gijón.

Fuente: Empresa Municipal de Aguas de Gijón. Elaboración propia, proyecto Anillo Navegable de Gijón.

La ciudad de Gijón presenta deficiencias graves en sus infraestructuras hidráulicas que determinan en gran medida el deterioro ambiental del río Piles en el tramo bajo hasta la desembocadura en la Playa de San Lorenzo. Las afecciones más significativas provienen de los vertidos directos de aguas contaminadas, de los aliviaderos de los colectores unitarios que, en situaciones de fuerte carga por el aporte de pluviales, vierten directamente al cauce las aguas residuales sin tratamiento previo. 


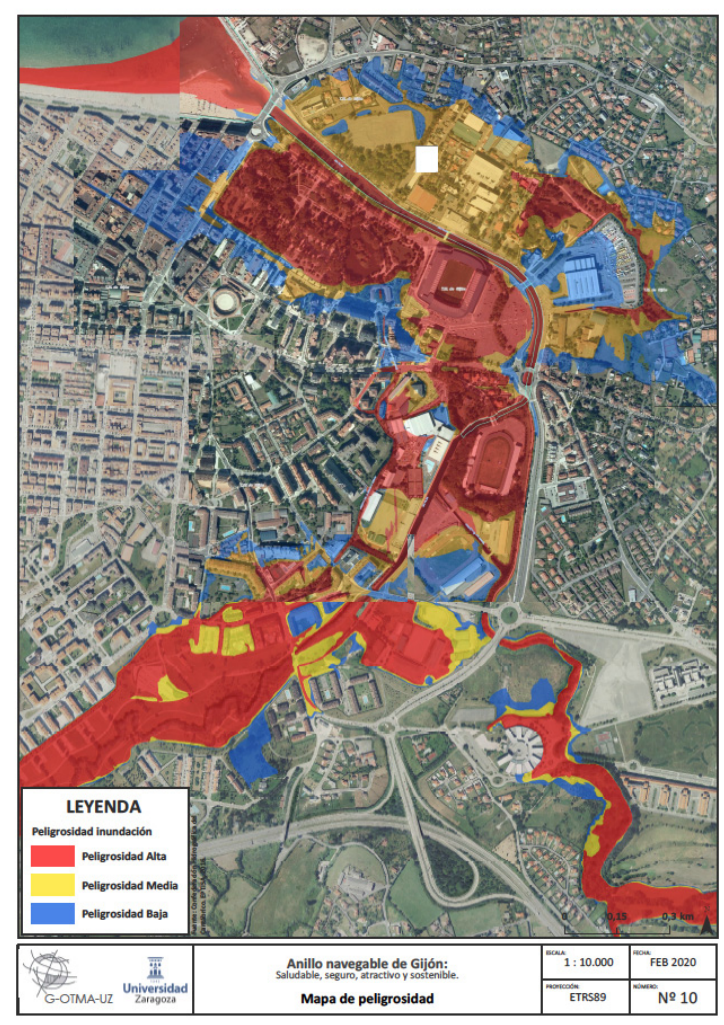

Figura 3. Mapa de peligrosidad por inundación de Gijón.

Fuente: Confederación Hidrográfica del Cantábrico. EPTISA, 2016.

Elaboración propia, proyecto Anillo Navegable de Gijón.

El Mapa de Peligrosidad muestra el grado de inundabilidad de la cuenca baja, coincidente con el tramo urbano de Gijón. El Plan de Gestión de Riesgo de Inundación (PGRI) es un documento fundamental para la gestión de las avenidas, una referencia para Administraciones y para la sociedad en general. Supone la última fase de implantación de la Directiva Europea sobre inundaciones. Mejora la coordinación y cooperación entre las administraciones y potencia la autoprotección incrementando la percepción social de los riesgos. Es la respuesta a la Directiva Europea de inundaciones. El plan implica a las distintas Administraciones con competencia en gestión de estos eventos (Comunidades Autónomas, Ayuntamientos, Confederaciones Hidrográficas, Dirección General de Sostenibilidad de la Costa y del Mar y Dirección General de Protección Civil) y su principal objetivo es aumentar la coordinación y cooperación entre ellas. 
La adecuada gestión del riesgo se mejora con el conocimiento que permite aumentar la capacidad de predicción ante situaciones de avenidas (tanto meteorológica como hidrológica) admitiendo siempre un margen importante de incertidumbre (Tabla 1). En la cuenca del Piles es notoria la carencia de estaciones meteorológicas y de aforo. A falta de datos validados por las administraciones competentes, asumimos como criterio orientativo los datos de caudales medios mensuales entrantes en el anillo (Piles y Peña Francia), tomados del estudio de la Politécnica de Madrid (2021), estimados utilizando el modelo SIMPA del Cedex (CEDEX, 2020).

En el caso de la precipitación hemos utilizado la base de datos SPREAD (Spanish PRecipitation At Daily scale) (Serrano-Notivoli, 2017). Dicha base de datos permite descargar la precipitación diaria para todo el territorio español con una resolución espacial de 5x5 kilómetros. Como la propia metodología de la base indica, la precipitación diaria se estimó para cada punto de la malla desde 1950-01-01 hasta 2012-12-31 y la malla se construyó mediante el paquete reddPrec (https://cran.r-project.org/web/packages/reddPrec). La información de precipitación observada comprende 12.858 estaciones proporcionadas por la Agencia Estatal de Meteorología (AEMET); el Ministerio de Agricultura y Medio Ambiente (MAGRAMA); el Servicio Meteorológico de Cataluña (METEOCAT); el Gobierno de Navarra y varias confederaciones hidrológicas.

A partir de la información descargada se calcularon la precipitación total promedio y máxima a escala mensual. Con la particularidad de que en este caso no se trata de un punto concreto donde se encuentra la estación meteorológica de referencia. En este caso la base de datos nos permitió estimar la precipitación para toda la cuenca del río Piles, la cual aparece resaltada en la mayor parte de las figuras anteriores. Además, con la intención de señalar aquellos eventos pluviométricos más destacados se calculo el percentil 95 de toda la serie (60.8 mm diarios). Utilizando este dato como límite señalamos el promedio de días que lo superaban cada mes. Suponiendo para la red de saneamiento y canalizaciones de la zona de estudio un grave riesgo de desbordamiento o afección.

Los datos obtenidos muestran que el riesgo ligado a un evento de precipitación notorio es más probable de lo que pensamos, principalmente en los meses de otoño e invierno. Eventos concretos donde la precipitación total mensual puede superar los 1000 mm y llegar a triplicar la precipitación total promedio de ese mes. Esto supone que la dinámica natural de las precipitaciones supone un problema grave para los sistemas de evacuación de la ciudad. Sobrepasando la capacidad de carga de la red unitaria actual de saneamiento de Gijón.

En los proyectos a desarrollar en el Piles hay que optimizar los sistemas de defensa y laminación de avenidas, disminuir la vulnerabilidad (vidas y bienes expuestos) de las zonas inundables y contribuir al buen estado ecológico de las masas de aguas en sus condiciones hidromórficas (tan complejas en un territorio urbano sometido por servidumbres históricas). 
Tabla 1. Distribución mensual del caudal medio y total de los ríos Piles y Peña Francia junto a la Distribución mensual de la precipitación en la cuenca del río Piles

\begin{tabular}{|l|c|c|c|c|c|c|c|c|c|c|c|c|}
\hline & Ene & Febr & Mar & Abr & May & Jun & Jul & Ago & Sep & Oct & Nov & Dic \\
\hline $\begin{array}{l}\text { Caudal medio } \\
\text { Piles (m } 3 / \mathrm{s})\end{array}$ & 1.4 & 1.3 & 1.1 & 1.1 & 0.9 & 0.55 & 0.35 & 0.3 & 0.3 & 0.6 & 1 & 1.3 \\
\hline $\begin{array}{l}\text { Caudal medio } \\
\text { Peña Fr. (m } 3 \text { s) }\end{array}$ & 0.4 & 0.4 & 0.35 & 0.35 & 0.3 & 0.25 & 0.2 & 0.15 & 0.15 & 0.15 & 0.3 & 0.35 \\
\hline $\begin{array}{l}\text { Caudal medio } \\
\text { total (m } \mathbf{3} \text { /s }\end{array}$ & $\mathbf{1 . 8}$ & $\mathbf{1 . 7}$ & $\mathbf{1 . 4 5}$ & $\mathbf{1 . 4 5}$ & $\mathbf{1 . 2}$ & $\mathbf{0 . 8}$ & $\mathbf{0 . 5 5}$ & $\mathbf{0 . 4 5}$ & $\mathbf{0 . 4 5}$ & $\mathbf{0 . 7 5}$ & $\mathbf{1 . 3}$ & $\mathbf{1 . 6 5}$ \\
\hline $\begin{array}{l}\text { Tiempos de } \\
\text { residencia (h) }\end{array}$ & $\mathbf{2 . 7 7}$ & $\mathbf{2 . 9 4}$ & $\mathbf{3 . 4 4}$ & $\mathbf{3 . 4 4}$ & $\mathbf{4 . 1 6}$ & $\mathbf{6 . 2 5}$ & $\mathbf{9 . 0 9}$ & $\mathbf{1 1 . 1}$ & $\mathbf{1 1 . 1}$ & $\mathbf{6 . 6 6}$ & $\mathbf{3 . 8 4}$ & $\mathbf{3 . 0 3}$ \\
\hline $\begin{array}{l}\text { Precipitación total } \\
\text { promedio (mm) }\end{array}$ & 421.4 & 355.2 & 326.8 & 375.4 & 299.4 & 214.4 & 172.4 & 227.2 & 298.3 & 454.1 & 506.1 & 496.1 \\
\hline $\begin{array}{l}\text { Precipitación total } \\
\text { máxima (mm) }\end{array}$ & 992.4 & 773.6 & 650.6 & 1045.2 & 966.2 & 908 & 672.5 & 755.6 & 901.5 & 1606.8 & 1034.8 & 1323.1 \\
\hline $\begin{array}{l}\text { Número días } \\
\text { supero percentil } 95\end{array}$ & 1.89 & 1.43 & 1.17 & 1.65 & 0.97 & 0.68 & 0.62 & 0.87 & 1.40 & 2.37 & 2.75 & 2.46 \\
\hline $\begin{array}{l}\text { Porcentaje días } \\
\text { supero percentil } 95\end{array}$ & 6.09 & 5.06 & 3.79 & 5.50 & 3.12 & 2.28 & 2.00 & 2.82 & 4.66 & 7.63 & 9.15 & 7.94 \\
\hline
\end{tabular}

En las propuestas que se plantean en este estudio se tiene en cuenta la amenaza de las avenidas que afectan al sector y se propone ampliar la sección hidráulica del anillo navegable. Siendo conscientes del riesgo, es preciso aprovechar las oportunidades de una reforma para adaptar el medio al paso de las avenidas y tener acceso a las herramientas necesarias para reducir al máximo los efectos.

Otro aspecto a tener en cuenta en el ámbito urbano abierto y periurbano, con mayor presión de actividades e infraestructuras, son las aguas pluviales, contaminadas por el lavado de playas de estacionamiento, carreteras y autopistas y césped (tratado con fertilizantes y plaguicidas). Las aguas pluviales son consideradas como una forma de fuente de contaminación no puntual. Por lo general, estos aportes entran en los sistemas de escurrimiento municipales y es descargada en los colectores. Cuando las precipitaciones son intensas, los colectores descargan por los aliviaderos directamente a los cauces. Sin embargo, no todas las escorrentías fluyen a los sistemas de drenajes antes de entrar a los cuerpos de agua. Algunos pueden desembocar directamente en los espejos de agua.

La contaminación en escorrentías urbanas no puede ser atribuida a una sola actividad o incluso a un grupo de actividades, porque no es causada por una actividad fácil de identificar y regular. Las fuentes de contaminación de escorrentías son tratadas como una verdadera fuente no puntual y las municipalidades deben trabajar para re- 
gularlas, prevenirlas y conducirlas a las plantas depuradoras bien directamente o mediante pozos de tormentas en los que se puede hacer acopio de las aguas más contaminadas de la primera escorrentía.

En conclusión, la calidad de las masas de agua de la cuenca del río Piles difícilmente alcanzará una buena calidad mientras no se considere la cuenca en su conjunto, se conozcan sus caudales y la calidad de las masas de agua, ni se actúe con medidas apropiadas conforme al carácter propio del territorio y no solo en los ámbitos urbanos, sino también en los espacios periurbanos y rurales. En el ámbito urbano es imperiosa la renovación y adaptación de las infraestructuras de saneamiento y depuración.

\section{El anillo navegable de Gijón}

El anillo navegable (Figura 4) es una instalación deportiva de propiedad pública, gestionada por el Ayuntamiento de Gijón mediante concesión, estando el río dentro del ámbito competencial del Dominio Público Marítimo Terrestre (DPMT), gestionado por el Principado de Asturias y el Dominio Público Hidráulico (DPH), competencia de la Confederación Hidrográfica del Cantábrico. Ambos sectores están claramente determinados. El tramo inferior del río Piles en el anillo navegable entra dentro del DPMT, mientras que el resto la instalación está incluida en el DPH.

La instalación deportiva es utilizada regularmente por unas 120 personas de distintas edades entre los que predominan las categorías infantiles que acceden desde el RGCC. No se tienen datos de los usuarios que acceden desde el centro deportivo municipal Las Mestas. También se desarrollan competiciones como el Trofeo de Piragüismo RGCC.

Si el anillo navegable dejara de existir sería prácticamente imposible el entrenamiento en esta zona de río, teniendo que desplazar a los niños, condicionados por los horarios de clases y demás. Este hecho haría imposible que se mantuviera este volumen de practicantes. En el período estival de los últimos años, el anillo no ha estado operativo y la actividad se ha desplazado al embalse de Trasona, donde se ha organizado un Campus de piragüismo. En el resto del año, utilizar instalaciones acuáticas fuera de la ciudad (embalse o similar) resulta muy gravoso en términos de movilidad, coste económico, pérdida de tiempo, de inseguridad y molestias del desplazamiento, además del impacto ambiental de las emisiones a la atmósfera ligadas al transporte. En consecuencia, este estudio rechaza la idea de trasladar el ANG del Piles a otro lugar, en coherencia con la apuesta por una ciudad de proximidad, conforme con un modelo de usos mixtos que limite las exigencias de movilidad y reduzca las distancias de los viajes dentro de la ciudad. Por todas estas razones, se considera que el impacto del cierre del anillo navegable sobre la actividad deportiva sería muy negativo, especialmente si se tienen en cuenta los tiempos y los horarios disponibles por los usuarios en edad escolar. 


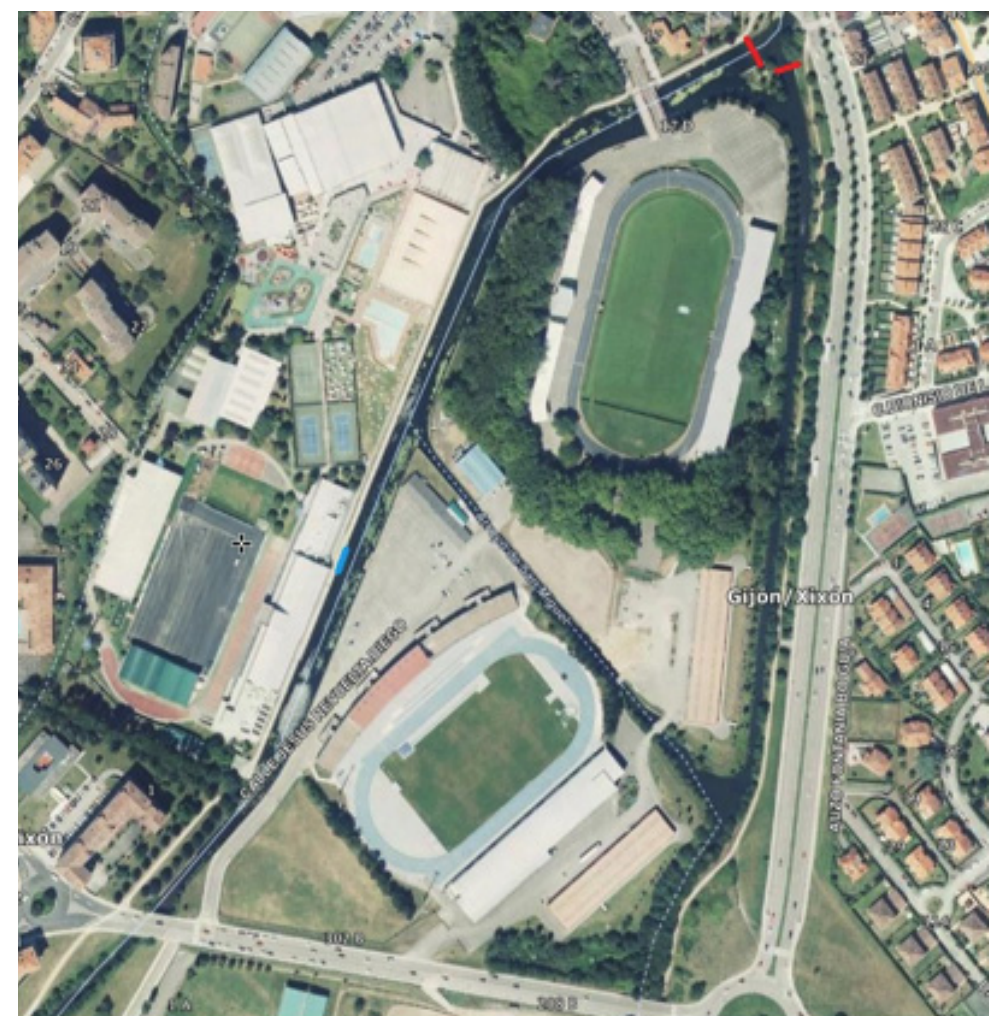

Figura 4. Anillo navegable de Gijón en la confluencia de los ríos Piles y Peña Francia. El circuito se cierra con el canal del Arroyo de San Miguel.

Fuente: PNOA, 2017.

Por el contrario, si la calidad del agua estuviese garantizada y la instalación fuera mejorada, aumentaría el número de practicantes ya que la calidad del agua es el principal motivo por el que los padres descartan el piragüismo como opción deportiva para sus hijos.

El anillo navegable de Gijón tiene unos valores intangibles, simbólicos e identitarios que son difíciles de evaluar y trasladar a índices operativos. Sin embargo, son fundamentales para el éxito de cualquier proyecto. Al respecto recogemos las declaraciones de Saúl Graviotto (deportista de élite y medallista olímpico, iniciado en el ANG) que expresan el sentir de muchos gijoneses:

"Ayer me enteré de una medida drástica que puede suponer la desaparición del piragüismo en Gijón y me gustaría lanzar un mensaje de apoyo para los cien- 
tos de compañeros que se verán afectados (la mayoría niños y niñas). A causa de la contaminación han decidido cerrar la única lámina de agua donde poder practicar piragüismo en la ciudad (el Anillo del Piles). La decisión ha sido la más fácil que se podía tomar, cerrarlo. Creo que los problemas se estudian y se afrontan poniendo otras alternativas en la mesa antes de dejar a tantos jóvenes sin practicar deporte. Por ejemplo, combatiendo la contaminación en lugar de fulminar un deporte con tanta tradición en Asturias. Invertir en deporte, nunca es malgastar dinero, es una forma indirecta de invertir en salud, educación y valores. Estoy convencido que a la larga, se acaba ahorrando. Espero que se reconsidere la decisión y sigan saliendo grandes piragüistas de Gijón" (Saúl Graviotto)

El anillo navegable tiene una longitud de $1.100 \mathrm{~m}$, anchura variable entre $24 \mathrm{~m}$ y 5 $\mathrm{m}$. Un canal curvo de $14 \mathrm{~m}$ de anchura cierra el circuito e intercomunica ambos ríos. Hacia el Sur, aguas arriba, el arroyo de San Miguel (5 m de anchura por 314 de longitud) cierra nuevamente el circuito e intercomunica el Piles y el Peña Francia. Una compuerta cierra el cauce del río Piles ( $16 \mathrm{~m}$ de longitud) y otra (12 $\mathrm{m}$ de longitud) el río Peña Francia. Ambas represan las aguas de los ríos Piles y Peña Francia procurando en el anillo navegable una profundad media de 1,2 $\mathrm{m}$, muy adecuada para la práctica de los deportes náuticos como piragüismo o kayak. El volumen de agua retenido se estima en $18.000 \mathrm{~m}^{3}$.

El conjunto del río Piles y el canal del Arroyo de San Miguel que conecta los ríos Piles y Peña Francia, está encauzado con muros de hormigón de altura variable entre 2 y 3 m de altura sobre el lecho del río. La obra se presenta sólida y sin deterioros apreciables. El cauce del río Peña Francia, en cambio, está flanqueado por escolleras bien asentadas. La parte no sumergible está colonizada por aneas y otras especies propias de ribera fluvial.

El embarcadero del RGCC se encuentra en la margen izquierda del canal encauzado del río Piles, aguas arriba del anillo navegable. Unas escaleras dan acceso a la plataforma de embarque que dispone además de un pontón flotante. En la orilla opuesta está el embarcadero público de las instalaciones municipales de Las Mestas, algo más sencillo y con socavamiento basal, que requiere reforma y consolidación.

En el primer tramo encauzado del río Piles hasta los embarcaderos se observan flechas de sedimentos fluviales de fracción grava y pequeños cantos de talla centimétrica (140 m y un espesor máximo de $35 \mathrm{~cm}$. en enero de 2020). Aguas abajo predominan los finos, arenas y limos acumulados preferentemente en las orillas convexas. Otra acumulación sedimentaria destacable se sitúa, dentro del anillo navegable, en la convergencia del río Peña Francia y el arroyo de San Miguel. En todo el tramo es frecuente encontrar restos leñosos arrastrados de la cuenca superior y depositados en el anillo navegable.

En el verano de 2020 se han identificado dos plantas vasculares, Ruppiamaritima y Potamogeton pectinatus (planta típicamente favorecida por eutrofización. Y con ellas 
aparecen (deducción por comparación con otras comunidades morfológica y fisionómicamente iguales encontradas en aguas salobres parecidas) clorofíceas filamentosas, sobre todo Cladophora (largos filamentos) y Spirogyra (masas viscosas sobre herbáceas).

El anillo navegable ha estado operativo desde 2003 y durante este período, según el informe del Patronato Municipal de Deportes, se han llevado a cabo diversas actuaciones de limpieza de algas, dragados y mantenimiento de compuertas. Dichas actuaciones, al parecer, no han evitado el crecimiento exponencial de algas en período estival en un medio acuático confinado, con alta carga de nutrientes y otros contaminantes, con intensa luminosidad, con elevada temperatura y escaso caudal del río en estiaje. En el citado informe, no se hace referencia a la renovación de la masa de agua retenida mediante la apertura periódica de las compuertas que permite el control de la temperatura y la concentración de organismos como las algas. Por otra parte, no existe ninguna rampa de acceso al cauce que facilite la entrada de vehículos para la extracción mecanizada de los aportes sedimentarios, por lo que las operaciones de dragado son laboriosas, incómodas y costosas.

\section{Sobre la calidad del agua y riesgo sanitario}

La disociación de una problemática sanitaria frente a la ecológica y/o ambiental ha sido utilizada por el Ayuntamiento de Gijón como el argumento último para justificar una serie de medidas en el entorno fluvial del río Piles, entre ellas la eliminación del anillo navegable. El riesgo sanitario en un sistema hidrológico no es un peaje asumible a cambio de su explotación, y su existencia constituye razón más que suficiente para corregir, limitar o suprimir-según el caso- la actividad humana causante del problema. Es a ese argumento al que se ha aferrado el Ayuntamiento de Gijón.

Dicho problema sanitario se focalizó desde un primer momento en la supuesta presencia y acumulación en el anillo navegable de algas tóxicas -cianobacterias-, organismos que típicamente proliferan en aguas eutrofizadas y con escasa renovación. De esta forma se responsabilizaba del problema a la existencia de barreras artificiales que ralentizan el flujo hídrico, justificando así la necesidad de "renaturalizar" el río. Además, en cierta forma se sacaban del foco muchos de los problemas endémicos del río Piles, es decir, la contaminación orgánica, los pequeños vertidos, los alivios de la red, etc. cuya responsabilidad última sería municipal.

La oposición del RGCC, entidad deportiva principal usuaria del anillo navegable, ha fomentado un intenso debate en torno a la problemática, el cual ha sacado a la luz los errores existentes en los informes manejados por el Ayuntamiento, y en su proceso de evaluación. Estos errores se podrían condensar en tres aspectos fundamentales que se exponen a continuación. 


\subsection{Dependencia excesiva de la hipótesis de partida}

La asunción como irrefutables de ideas expresadas en informes o escritos precedentes, y la falta de análisis posteriores que permitieran confirmarlas o descartarlas. Este hecho se ejemplifica a la perfección en la importancia dada por el Ayuntamiento y por los estudios posteriores a una notificación emitida en julio de 2004 por parte de la Agencia de Sanidad Ambiental y Consumo de la Consejería de Salud y Servicios Sanitarios del Principado de Asturias. En ella se expone que "la presencia de dichas cianoficeas en el anillo podría ser causa de alergias cutáneas y otras alteraciones, señalando que la única medida efectiva para evitar su aparición sería desembalsar el agua y limpiar el anillo". Una lectura atenta de dicho informe permite concluir de forma inequívoca que dicha afirmación es meramente especulativa y que no existe ningún análisis que la respalde. No obstante, esa idea no contrastada fue tomada como punto de partida en sucesivos informes y como prueba fehaciente de la existencia de proliferaciones de cianobacterias, y acabó dándose por válida por parte de la Administración.

\subsection{Escasa adecuación de los perfiles profesionales involucrados en el estudio}

Es de sobra conocido que la intervención de equipos multidisciplinares, y la inclusión de perfiles especializados, es un factor fundamental para el correcto desarrollo de estudios de evaluación ambiental. Sin pretender infravalorar el esfuerzo y la capacidad de las personas involucradas, es necesario poner de relieve que en los diferentes estudios licitados por el Ayuntamiento se han detectado carencias significativas derivadas de este problema. Dos son los estudios principales en los que se ha basado el ayuntamiento para la valoración del problema, los cuales se analizan a continuación:

\subsubsection{Evaluación del estado hidrobiológico del río Piles en su tramo urbano y propuesta de medidas de gestión}

Se trata de un estudio licitado de forma urgente por el Ayuntamiento de Gijón, elaborado por la Ingeniería UVANT (2020) para tener un diagnóstico del problema en un tiempo claramente inferior al necesario. Adolece de una insuficiente carga analítica, se basa excesivamente en trabajos e informes previos, y presenta un enfoque demasiado sesgado. Tres grandes problemas son detectados en dicho estudio:

\subsubsection{Valoración de la calidad del agua en el sistema hidrológico}

El estudio de Uvant intenta una doble aproximación, realizando por un lado una caracterización del estado trófico del sistema, y por otro lado un análisis del potencial 
ecológico. La caracterización del estado trófico se realizó basándose en imágenes de satélite y empleando un modelo previamente utilizado en la Albufera de Valencia. Sin embargo, la ausencia de una validación in situ para el sistema del río Piles, y la aplicación de un algoritmo de ajuste erróneo inhabilitan totalmente el análisis.

En lo que se refiere al análisis del potencial ecológico, los problemas surgen de una inadecuada interpretación de las directrices marcadas por la Directiva Marco de Aguas y de los protocolos que de ella derivan. La incorrecta elección de los índices a evaluar, la ausencia de definición de la tipología de la masa de agua a estudiar y de sus condiciones de referencia, la mala elección de los puntos de muestreo, etc. lastran la posibilidad de un adecuado diagnóstico.

\subsubsection{Presencia de cianobacterias en el anillo navegable}

Basándose en el informe anteriormente citado de la Agencia de Sanidad Ambiental, y en la existencia de proliferaciones de cianobacterias en un ecosistema lagunar próximo al río, se asumen como seguras las proliferaciones en el anillo, aún sin ningún estudio ni analítica que las confirme. Siendo obvio que la presencia de cianobacterias no es descartable - puesto que de forma natural forman parte de las comunidades acuáticas de prácticamente todos los ecosistemas-, afirmar la existencia de proliferaciones sin ningún dato que lo respalde es un error manifiesto.

\subsubsection{Análisis de las causas de los problemas de contaminación, malos olores y mortandades de fauna en la zona de desembocadura del río Piles y playa de San Lorenzo}

El río Piles es un ecosistema sometido a una fortísima presión antrópica. Son de sobra conocidos los exagerados niveles de contaminación orgánica presentes en el río (datos del propio Ayuntamiento y de la Confederación Hidrográfica del Cantábrico), así como la existencia de alivios recurrentes de la red de colectores en momentos de alta pluviosidad, y el frecuente aporte de vertidos sin depurar desde múltiples instalaciones anexas al río, etc. Sin embargo, en el informe de Uvant se insiste en la potencial causalidad de las cianobacterias y cianotoxinas del anillo navegable, las cuales debemos recordar nunca han sido constatadas, como fuente de los problemas de salubridad en la zona de desembocadura del río. 


\subsubsection{Estudio del nivel de salubridad de las aguas continentales y litorales de Gijón. 2020}

Elaborado por un equipo multidisciplinar de la Universidad de Oviedo (2021), a diferencia de en el caso anterior estamos ante un estudio bien planificado, con un diseño adecuado, y una carga analítica muy importante. Los problemas detectados en este caso no se relacionan con los resultados obtenidos, sino que se deben únicamente a la interpretación y puesta en contexto de los mismos. El problema radica, una vez más, en una excesiva dependencia de la hipótesis de partida, es decir, la supuesta existencia de proliferaciones de cianobacterias y algas tóxicas en el anillo navegable.

El estudio se estructuró en tres grandes bloques: la detección de las condiciones ambientales y físico-químicas favorables para el desarrollo de proliferaciones de cianobacterias, la caracterización taxonómica de las comunidades fitoplanctónicas, y el análisis de toxinas. Siguiendo ese esquema, y partiendo de la idea de que un sistema con alto contenido en nutrientes y escasa circulación del agua es el contexto ideal para el desarrollo de proliferaciones tóxicas, los autores asumen como cierto el desarrollo de las mismas. Los resultados obtenidos muestran la presencia puntual de cianobacterias en el medio, y llegan a detectar en una ocasión la presencia de cianotoxinas.

Es fundamental tener en cuenta en este punto que la presencia de cianobacterias en un ecosistema no constituye un problema en sí misma, sino que el problema surge cuando las cianobacterias proliferan y alcanzan abundancias muy altas. Los niveles detectados en el anillo navegable del río Piles no son en ningún caso significativos, situándose muy por debajo de los umbrales de riesgo marcados por las recomendaciones de la OMS para aguas de uso recreativo o lúdico, e incluso por debajo de los valores legislados para aguas de consumo humano. Es esta falta de puesta en contexto la que lastra en gran medida las conclusiones del estudio de la Universidad de Oviedo.

\subsection{Falta de revisión crítica}

Se trata sin duda de un problema muy extendido dentro del esquema de funcionamiento de la Administración Pública. La falta de tiempo, el exceso de confianza, o la ausencia de perfiles especializados en el personal propio de la Administración, suele conducir a dar por válidos los resultados de todos los informes que encarga. En ocasiones esto se ha revelado como un problema, y ha generado un círculo vicioso, en el que con demasiada frecuencia el nivel de exigencia en la calidad de los estudios ha caído en picado. En contadas excepciones, una de ellas la que nos ocupa, la aparición de contestación social puede llevar a la detección de esas deficiencias. 


\section{Análisis DAFO}

Una vez descrita e identificada la cuenca del río Piles y el anillo navegable de Gijón y definido el desafío de la conservación del equipamiento deportivo en condiciones ambientales saludables y económica y socialmente viables, se ha procedido al análisis y diagnóstico con la herramienta o técnica DAFO muy apropiada para conocer la situación en la que se encuentra el proyecto y establecer la base de un plan estratégico con el que afrontar la conservación y aprovechamiento del anillo navegable en el futuro a corto, medio y largo plazo. El análisis DAFO ha procurado un mapa o matriz cuadrada para la toma de decisiones con una visión estratégica, sin la cual se corre el riesgo de tomar decisiones simples de forma automática o irracional que pueden abocar al fracaso de un proyecto.

El DAFO realizado estudia las Debilidades, Amenazas, Fortalezas y Oportunidades del anillo navegable del Piles. Un análisis interno y externo del entorno ambiental y social en el que se desarrolla la actividad deportiva para mejorar su idoneidad, sus prestaciones, su funcionamiento y su posicionamiento en un río saludable, seguro, atractivo y sostenible dentro de la ciudad. El mapa DAFO muestra el actual estado del anillo navegable en función de sí mismo y del entorno en el que se desarrolla o desea desarrollarse. Es el punto de partida para realizar un análisis proyectivo.

\subsection{Análisis interno: debilidades y fortalezas}

En el estudio interno, el objetivo es encontrar las debilidades y las fortalezas que tiene el anillo navegable: las primeras para corregirlas y las segundas para impulsarlas (Figura 5).

\subsection{Análisis externo: amenazas y oportunidades}

El análisis externo es el que se refiere al entorno funcional del anillo. Incluye todos aquellos aspectos que no dependen directamente de la actividad deportiva y sus instalaciones pero que le afectan. Estos puntos son muy reveladores a la hora de definir estrategias que permitan combatir las amenazas y aprovechar las oportunidades (Figura 6).

Gracias a la elaboración de la matriz DAFO se ha sistematizado la información de modo operativo y se ha definido una estrategia que permita aprovechar las oportunidades detectadas, corregir las debilidades que existen y preparar la organización para hacer frente a las amenazas que se le presentan. 


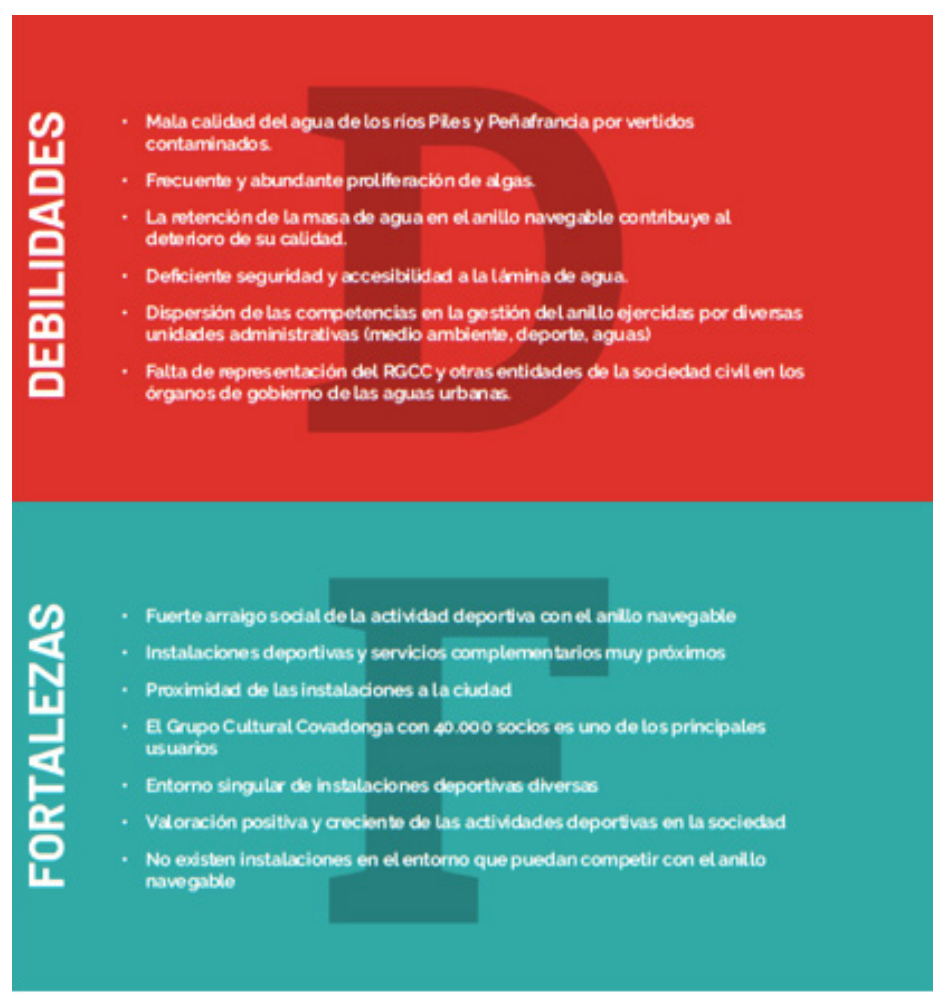

Figura 5. Cuadro de fortalezas y debilidades del anillo navegable. Fuente: RGCC, 2020.

Los objetivos se han jerarquizado en función de las prioridades marcadas. Las metas a conseguir son lo más tangibles posibles y flexibles para poder corregir, modificar o crear determinados procesos.

A partir del DAFO, se ha implementado el CAME, que es el que permite y responde a las siglas de Consolidar las fortalezas, Aprovechar las oportunidades, Minimizar las debilidades y Eliminar o reducir las amenazas. En el diagnóstico estratégico se combinan las fortalezas y las oportunidades para conseguir las potencialidades. Lo mismo pasa cuando se combinan las debilidades con las amenazas, puesto que así se puede tomar conciencia de las limitaciones, desafíos o riesgos.

Así se ha fijado la estrategia que rige las propuestas que podrán conducir el desarrollo del proyecto de la recuperación integral del río Piles compatible con el anillo navegable de Gijón. 


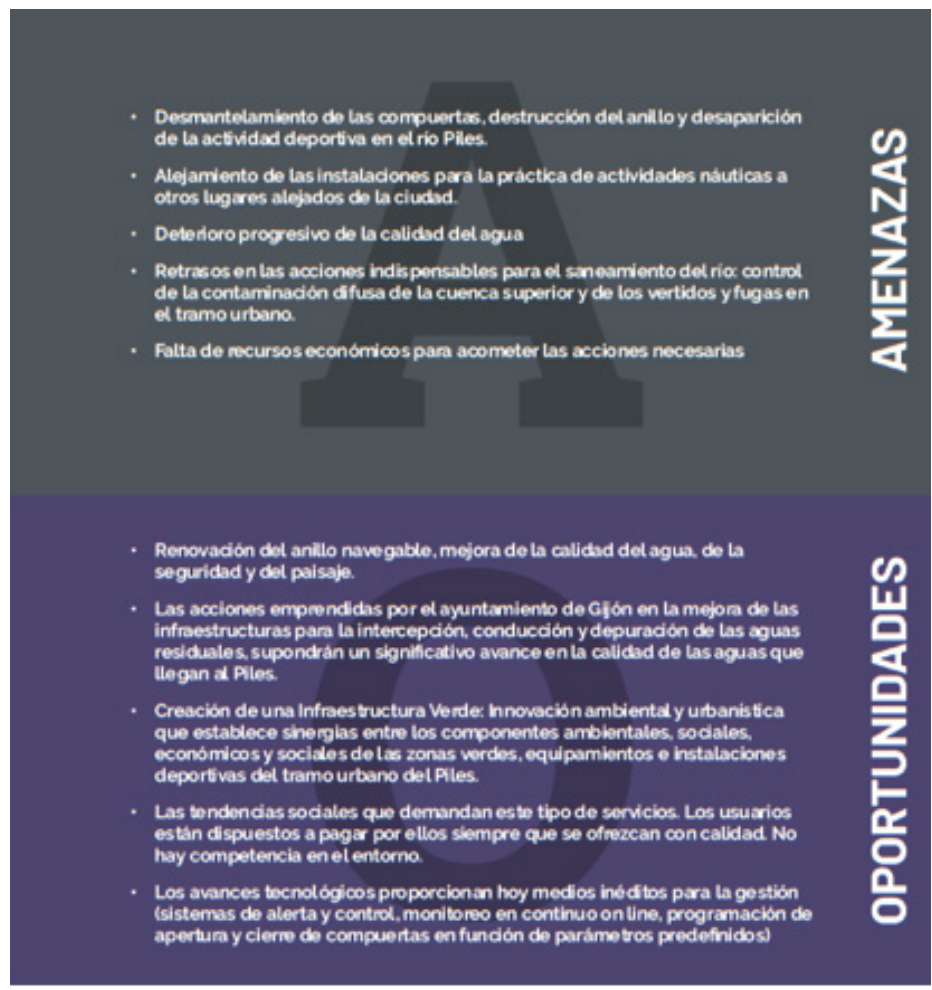

Figura 6. Cuadro de amenazas y oportunidades del anillo navegable.

Fuente: RGCC, 2020.

\section{Propuestas}

Conforme a la estrategia definida tras el análisis DAFO y el marco conceptual y normativo expuesto en la primera parte de este estudio, se plantean un paquete de propuestas ordenadas en función de su carácter, urgencia, viabilidad y coste presupuestario.

1. Creación de un órgano supramunicipal. Como punto de partida, se plantea la creación de un órgano supramunicipal con representación de las administraciones implicadas en garantizar la continuidad del corredor fluvial del río Piles desde su nacimiento hasta su desembocadura. Es importante que se integren las diferentes áreas municipales afectadas del Ayuntamiento (infraestructuras, medio ambiente, deporte), la Confederación Hidrográfica del Cantábrico y el Principado (Gestión del dominio público marítimo-terrestre). En este órgano deben estar representadas, además, las entidades sociales, ambientales, culturales, deportivas, 
ambientalistas, agricultores y ganaderos y otros usuarios de la cuenca del río Piles. Su principal función consiste en coordinar de forma eficiente y transparente, todos los estudios, proyectos y actuaciones en la cuenca del Piles. La experiencia del proyecto de recuperación del río Oria (Guipúzcoa) o Ebro Resilience en el tramo medio del Ebro, liderado por el Ministerio de Transición Ecológica y Reto Demográfico, con apoyo de la UE, pueden ser buenos referentes. La UE insta a todos los entes locales y regionales a movilizarse en todas las políticas sectoriales afectadas y, en particular, a través de su competencia de gestión del territorio y de urbanismo, a fin de planificar y organizar la infraestructura verde.

2. Infraestructura Verde de Gijón. Como estrategia integradora de las diversas acciones a emprender, se propone el diseño de la Infraestructura Verde de Gijón (Figura 7) para garantizar la coherencia de los diversos proyectos. El concepto de infraestructura verde está claramente definido y entra de lleno en las políticas desarrolladas por Ministerio para la Transición Ecológica y Reto Demográfico, la Agenda Urbana Española, el Pacto Verde Europeo, y la Estrategia Europea de Biodiversidad. El concepto de Infraestructura Verde se incorpora al ordenamiento jurídico español en la Ley 33/2015, de 21 de septiembre, por la que se modifica la Ley 42/2007, de 13 de diciembre, del Patrimonio Natural y de la Biodiversidad. Una infraestructura verde es una red de zonas naturales y seminaturales, y de otros elementos ambientales, planificada de forma estratégica, diseñada y gestionada para el mantenimiento, restauración y mejora de los ecosistemas y sus servicios ecosistémicos. Incorpora espacios verdes o azules (ecosistemas acuáticos) y otros elementos físicos de espacios terrestres (incluidas las zonas costeras) y marinos. En los espacios terrestres, la infraestructura verde está presente y articula la conexión de los entornos rurales y urbanos.

El Dictamen del Comité de las Regiones - Infraestructura verde mejora del capital natural de Europa (DOCE 5/12/2013) destaca la importancia del concepto de Gobernanza compartida: subraya que la clave del éxito de la puesta en marcha de la infraestructura verde reside en la cooperación entre todos los niveles de gobierno y en la aplicación efectiva de los principios de gobernanza multinivel, así como en la participación de todos los agentes, de todas las partes interesadas e incluso de los ciudadanos a nivel local en su diseño y aplicación. El conjunto de los ríos Piles y Peña Francia en el tramo urbano de Gijón reúne unas condiciones excepcionales para articular un eje de la Infraestructura Verde de Gijón, conforme a la Estrategia de la UE sobre la biodiversidad.

Finalmente hay un aspecto sobresaliente que no ha recibido la suficiente atención. En la matriz azul y verde de la playa de San Lorenzo y los ríos Piles y Peña Francia se inscribe uno de los conjuntos deportivos más importantes y diversos de España (Puerto deportivo, playa de San Lorenzo, Palacio de los Deportes, Estadio El Molinón, complejo deportivo Las Mestas, Club Hípico Astur, instalaciones deportivas del RGCC y de la universidad hasta el Hospital de Cabueñes). La ciudad de Gijón está volcada con el deporte y ofrece a los visitantes una cultura deportiva en- 
vidiable y unas facilidades difícilmente superables. Además, en los corredores fluviales del Piles y Peña Francia se han instalado el Palacio de Congresos, la Feria de Muestras, Museo del Pueblo de Asturias, Campus de Gijón de la Universidad de Oviedo, Escuela Politécnica, Laboral Ciudad de la Cultura y Parque Científico Tecnológico entre otros equipamientos que constituyen elementos de centralidad urbana de primer orden que dotan de vitalidad cultural, social y económica a la infraestructura verde. Invertir en la infraestructura verde es revitalizar la ciudad.

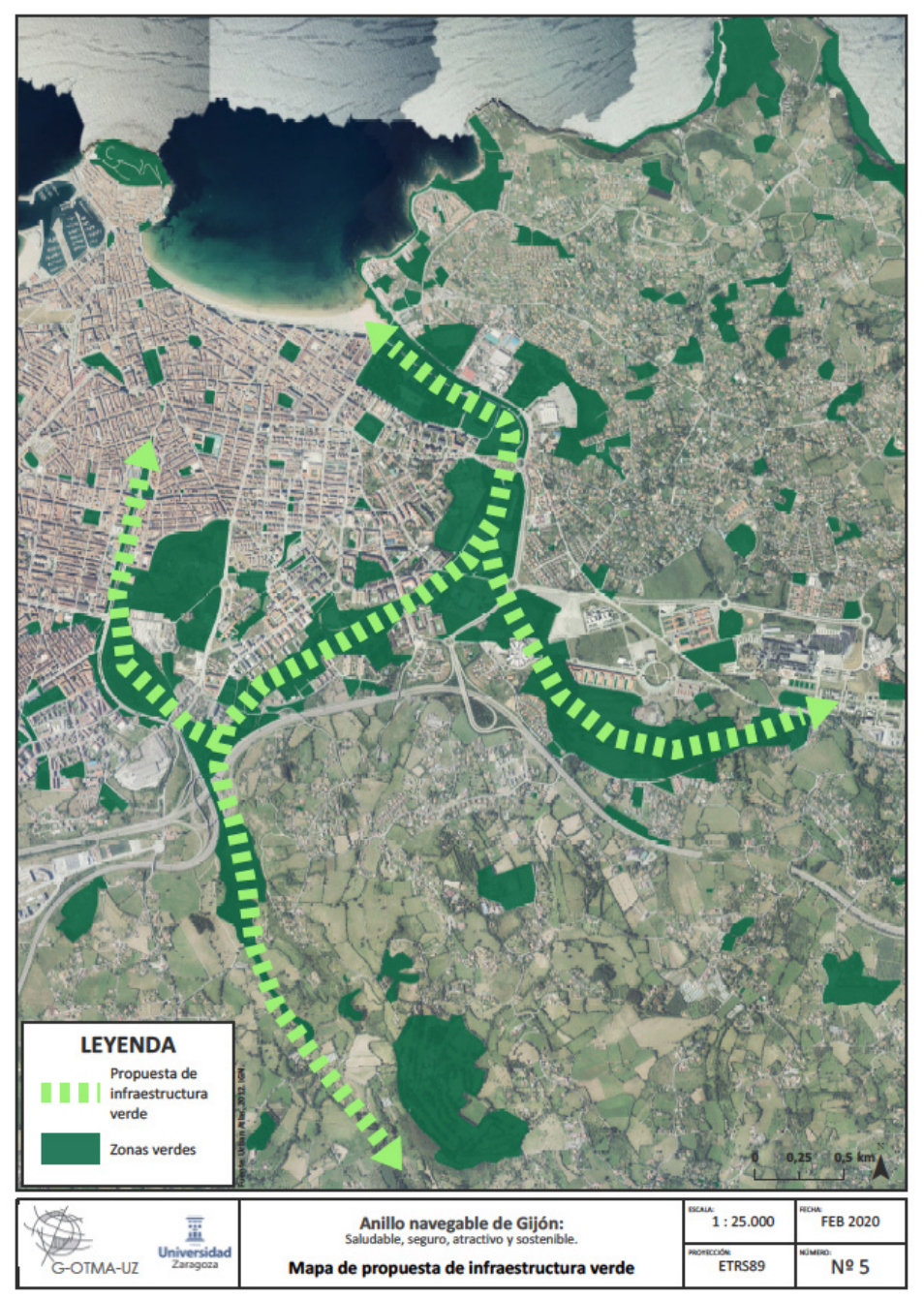

Figura 7. Mapa de infraestructuras verdes de Gijón.

Fuente: Urban Atlas, IGN 2012. Elaboración propia, proyecto Anillo Navegable de Gijón. 
3. Recuperación de las riberas del Piles en el tramo del anillo navegable de Gijón. Esta propuesta requiere un proyecto urbanístico y paisajístico, además de un cambio drástico en el sistema de gestión.

3.1. Mejoras urbanísticas y del paisaje. El actual anillo navegable discurre, como ya se ha indicado, entre muros de hormigón que no aportan mucho al disfrute de la actividad deportiva en un entorno de aspecto agradable. La medida propuesta lleva consigo una considerable mejora paisajística más acorde con un espacio seminatural y una significativa mejora en la seguridad y accesibilidad a la lámina del agua. El concepto a desarrollar se concibe como un híbrido entre gradas de estadio y ribera verde, conforme a la función deportiva de la instalación, el carácter urbano del lugar y el necesario respeto del río y la puesta necesaria puesta en valor del paisaje. Además, amplía la sección hidráulica del cauce y reduce la inundabilidad de las instalaciones próximas.
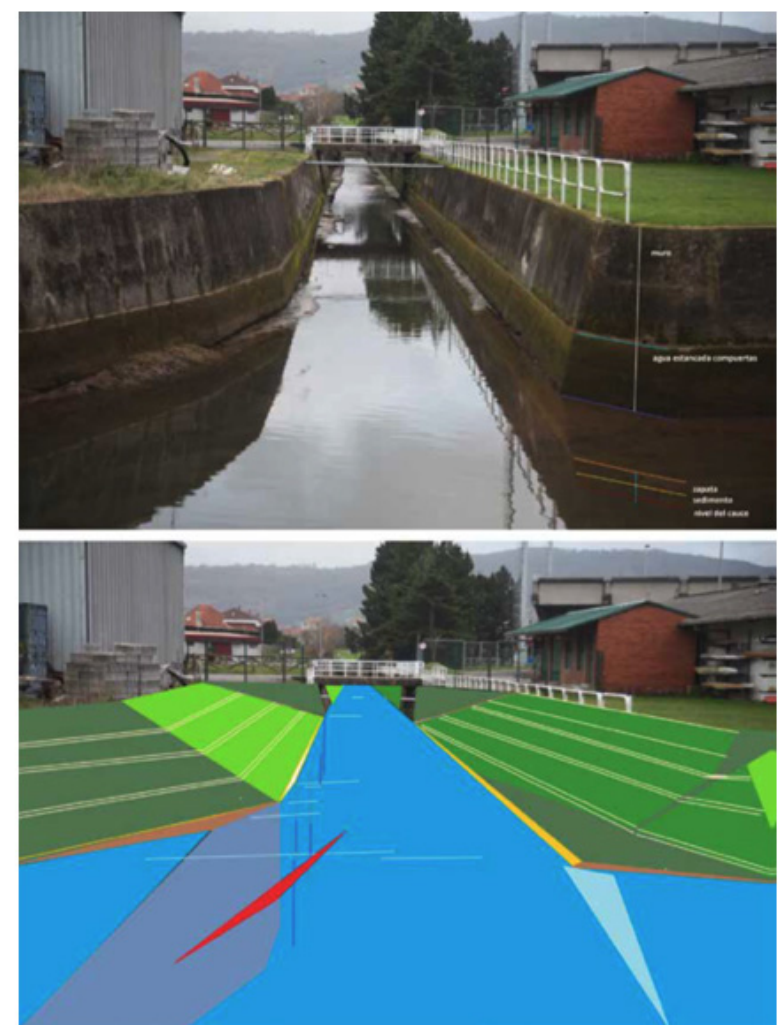

Figura 8. Estado actual e infografía del concepto a desarrollar aplicado al Arroyo de San Miguel.

Foto y diseño: F. Pellicer. 
La actuación consiste básicamente en el rebaje de los muros hasta el nivel del agua embalsada y creación de rampas verdes escalonadas de hierba con gradas de madera que faciliten la contemplación del espectáculo o actividad en condiciones de seguridad. La estabilidad de las rampas y rellanos con césped puede reforzarse con mallas verdes tridimensionales ancladas en el suelo (Figura 8). Las gradas situadas en los lugares con mejores panorámicas, no ocupan la totalidad del anillo, sino que alternan con tramos de vegetación natural de ribera. En esta propuesta caben variables más ambiciosas como la de extender la actuación a todo el espacio disponible en el entorno de Las Mestas eliminando rellenos, superficies impermeables, áreas de aparcamiento y edificios obsoletos o sin uso. Buena parte del espacio circundante a los estadios puede ser rebajado a cota natural del terreno ampliando notablemente la sección hidráulica y aplicando las técnicas más avanzadas para la regeneración espontánea de la vegetación propia de ribera (modelo: "Jardines en movimiento" de Gilles Clément), donde los jardines y el paisaje no son espacios estáticos que deben controlarse, sino lugares donde la naturaleza sigue su curso, donde las especies vegetales se instalan de forma espontánea y se desarrollan libremente siguiendo los procesos de sucesión biológica (Figura 9).

3.2. Sobre la gestión de la masa de agua del anillo navegable.

Es un aspecto fundamental para evitar la eutrofización y el calentamiento del agua y el consiguiente desarrollo de algas, especialmente de las potenciales aglomeraciones que interfieran en el desarrollo de las actividades deportivas o que puedan suponer un riesgo para la salud de los usuarios. Para ello es imprescindible la renovación continua de la masa de agua retenida por las compuertas. Como punto de partida debe quedar claro que el correcto manejo de las compuertas requiere un estudio específico de los caudales fluviales y del régimen de las mareas y su afección al área de estudio. Se carece hasta el momento de datos suficientemente fiables sobre los caudales circulantes por el río Piles y río Peña de Francia, así como el régimen de las mareas que alcanzan al anillo navegable. En todo caso, en el proceso de llenado del anillo navegable con aportes fluviales deben respetarse rigurosamente los caudales ecológicos. Asimismo, el proceso del vaciado debe hacerse de manera que no se alteren sustancialmente las condiciones hidrodinámicas naturales que pudieran afectar a la fauna o al flujo de sedimentos.

Actualmente las ingenierías especializadas ofrecen una amplia tipología de las compuertas (metálicas hidráulicas, neumáticas) a instalar y de manejar para el vaciado y llenado automático o manual del anillo navegable. Su gestión puede modelizarse para operar conforme a los datos de caudal, temperatura del agua, indicadores hidrobiológicos y la programación de actividades para los usuarios. En el diseño técnico de las compuertas ha de tenerse en cuenta la solera que debe permitir el vaciado completo, la flexibilidad de operación para interferir lo menos posible en los flujos hídricos fluviales y las mareas, en su integración en el paisaje. 


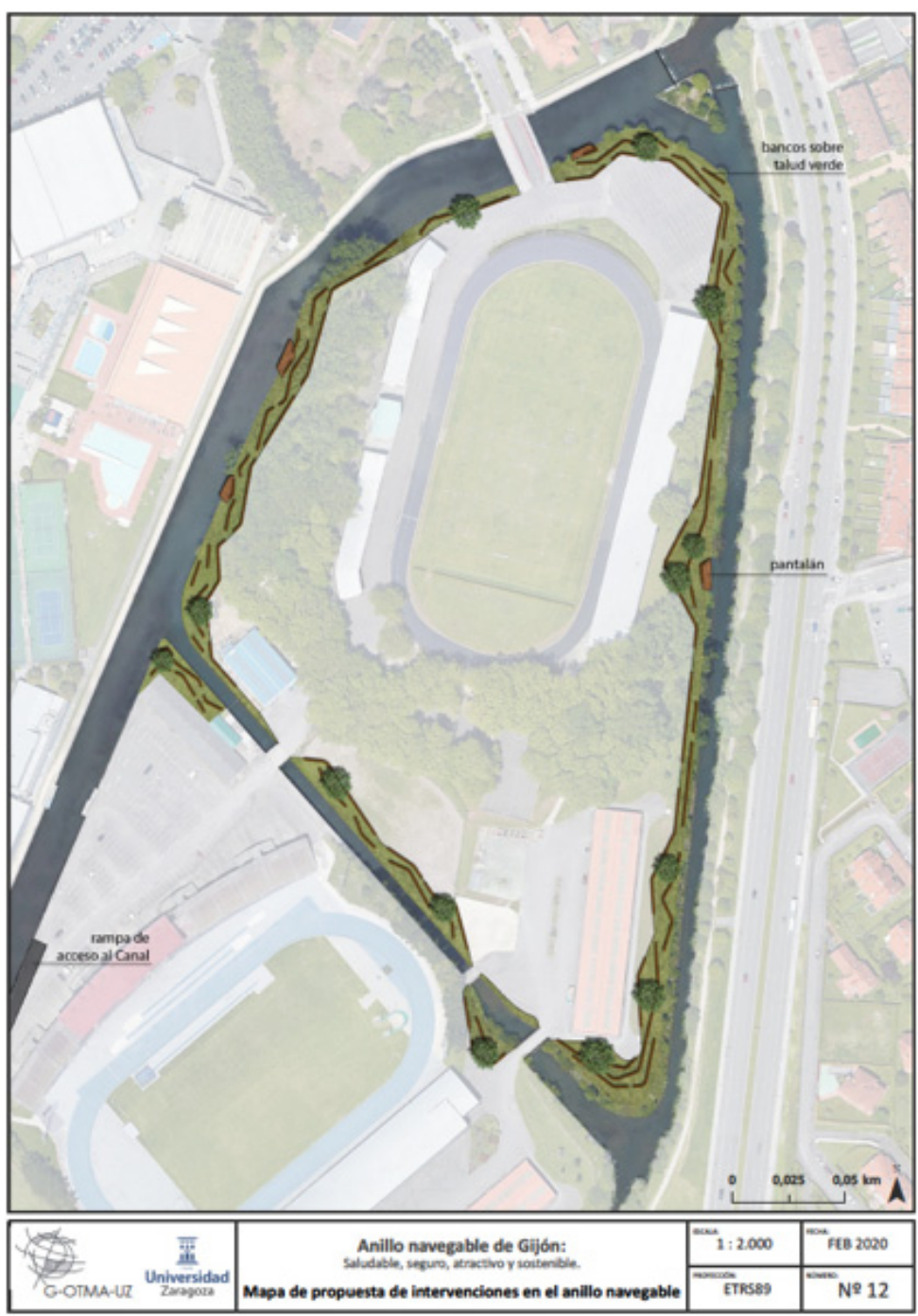

Figura 9. Plano de propuesta de intervención en el anillo navegable. Fuente: Elaboración propia, proyecto Anillo Navegable de Gijón.

3.3. Para el mantenimiento del vaso en condiciones de seguridad y el correcto desarrollo de las actividades deportivas, se propone la construcción de una rampa que permita el acceso de maquinaria apropiada para retirar los sedimentos y otros materiales arrastrados (troncos, residuos voluminosos...). El lugar más adecuado es sobre la orilla derecha del río Piles, aguas arriba del 
embarcadero, justo en el lugar en que se depositan las flechas de gravas fluviales. Hay terreno disponible de titularidad pública, no hay equipamientos o servicios que pudieran ser afectados y, además, tiene una accesibilidad muy buena. La realización de esta obra revierte en la simplificación y disminución de los costes de la operación hasta el momento bastante costosa. La deseable devolución de estos materiales al río aguas abajo no tiene sentido en este caso, pues el tramo inferior del río es un simple canal que conduciría los residuos retirados del anillo navegable directamente a la playa de San Lorenzo, donde tendrían que retirarse de nuevo.

\section{Conclusiones}

El estudio de caso analizado en Gijón muestra una forma de intervenir en la planificación de espacios complejos, sujetos de conflictos e intereses, como son los espacios fluviales urbanos donde se dan cita los procesos hídricos, geomorfológicos y ecológicos con los factores sociales, económicos y culturales, algunos de ellos intangibles -simbólicos, estéticos, afectivos- pero de fuerte significación. La ciencia geográfica aplicada, por su posición en el conjunto del conocimiento, resulta particularmente útil para el análisis y presentación de alternativas a problemas complejos que requieren colaboración transdisciplinar.

La aportación geográfica en este caso sitúa el conflicto político social del anillo navegable de Gijón en su verdadero contexto. El problema del río Piles no se elimina destruyendo una instalación deportiva para mejorar las condiciones hidrogeomorfológicas del río o evitar riesgos sanitarios provocados por unas potenciales aglomeraciones de cianobacterias tóxicas. Es un problema de planificación urbana y medioambiental que implica a componentes naturales y también los sociales, económicos y culturales. Un problema que se agrava cuando se amenaza con destruir unas instalaciones y una práctica deportiva fuertemente ligada a la ciudad. El desafío de la regeneración del río Piles abarca toda la cuenca, si bien se agudiza en el tramo urbano donde van a parar al río vertidos incontrolados, fugas de la red de saneamiento, aguas residuales mezcladas con pluviales en los momentos siguientes a las intensas precipitaciones. El anillo navegable, objeto de este estudio, sufre más que genera los efectos un sistema fluvial fuertemente degradado.

La mirada geográfica abre el amplio espectro de elementos y factores que configuran el sistema río-ciudad para facilitar, a un tiempo, la necesaria evacuación de las aguas de la cuenca superior adaptando el espacio al paso de las avenidas, para garantizar la seguridad frente a los riesgos sanitarios y para procurar el acercamiento y disfrute del río como un bien patrimonial de la ciudad, en el que se contemplen diversos escenarios con distinto grado de naturalidad y de intervención cultural, ligados por una estrategia de complementariedad de funciones y compatibilidad de usos. De este modo el análisis geo- 
gráfico se alinea en el marco conceptual y normativo de las administraciones europeas y españolas competentes en materia de desarrollo urbano y transición ecológica.

Así planteado y descendiendo al plano operativo, este estudio geográfico plantea una serie de acciones estratégicas a desarrollar en sucesivas fases conforme a la urgencia y necesidad de intervención, a las disponibilidades económicas y a las alianzas entre instituciones y con patrocinadores. Unas son acciones de intervención muy concretas, urgentes, viables y de bajo presupuesto; otras tienen un alcance espacial y temporal superior, y requieren la coordinación institucional, el apoyo y consenso social y un presupuesto mayor. Unas y otras están imbricadas conforme a un proyecto global e integral de la cuenca del río Piles. Las acciones concretas se concatenan con otras de mayor calado en un proyecto estratégico de larga trayectoria que viene a corregir la degradación secular que padece el río Piles a su paso por Gijón.

Entre las medidas concretas, viables, urgentes, eficientes y de bajo presupuesto destacan el control periódico y frecuente de la calidad del agua entrante en el vaso del anillo navegable y la renovación frecuente del agua retenida mediante la gestión de la apertura y cierre de las compuertas. Estas simples medidas tendrán sin duda efectos muy positivos sobre la calidad de las masas de agua circulantes y de las temporalmente retenidas, reduciendo hasta niveles inapreciables el impacto del anillo navegable. Pero de poco servirán si no se corrigen los impactos estructurales que suponen los vertidos directos de las aguas residuales tanto de forma difusa en el medio rural como de forma concentrada en el medio urbano.

Otras medidas requieren un mayor esfuerzo inversor y mayor coordinación institucional: el rebaje de los muros de hormigón hasta la cota del canal de navegación y creación de taludes revegetados con especies propias de ribera conforme al modelo de "jardín en movimiento " de Gilles Clément. La creación de taludes lleva consigo la ampliación de la sección hidráulica y el consiguiente aplanamiento de los picos de las crecidas disminuyendo el peligro de las inundaciones. El mantenimiento del canal de navegación con la regularidad que requiera, utilizando medios mecánicos eficientes y menos costosos que los empleados hasta ahora. El dragado de los bancos aluviales sólo parece necesario en caso de que su volumen agrave de manera significativa la práctica deportiva del canal navegable o el riesgo de inundaciones. En ningún caso se introducirán elementos que obstaculicen el flujo natural de las aguas y de las especies o disminuyan la sección hidráulica del cauce.

Finalmente, se platea una operación estratégica de orden estructural para la ciudad: la creación de una infraestructura verde que conecte el medio natural y rural con el urbano a través de una red de espacios y corredores verdes y azules (ríos y riberas) del río Piles en Gijón. El anillo navegable en este contexto representa una rótula en la que interactúan de modo compatible los elementos naturales y urbanos. La operación se complementa con la creación de un órgano supramunicipal para la gestión de la vida y los recursos hídricos de la cuenca del Piles. 
La historia del río Piles inicia un nuevo capítulo. En la actualidad los ríos ya no se miran como amenazas o como cloacas sino como elementos del patrimonio natural que hay que cuidar y disfrutar. La historia del Piles en el año 2021 se escribe con la renovación de las redes de saneamiento, la depuración de las aguas residuales y su reversión en buenas condiciones al medio natural, la mejora de los cauces y llanuras de inundación liberando espacio para el cauce y las riberas, el aprovechamiento de los servicios ecosistémicos y el disfrute de equipamientos deportivos en un entorno natural. La coordinación institucional y la participación activa y corresponsable de la ciudadanía serán fundamentales en este recorrido hacia el futuro. Las entidades sociales vinculadas con el río Piles quieren estar presentes en el proceso de construir un futuro con el río y el deporte.

De esta manera la naturaleza y la ciudad se reconocen y el río se convierte en cultura en el ámbito urbano. No se trata de glorificar los aspectos ambientales sino de hacer cultura con la naturaleza en la ciudad. Esta fusión profunda de río y ciudad, sujeto de crisis, conflictos e intereses, es una de las manifestaciones más ricas de la vitalidad de una ciudad. Los espacios fluviales urbanos son un fiel exponente de la calidad ambiental, de la eficacia en la gestión y de la cultura y civismo de sus habitantes.

\section{Bibliografía}

Agenda Urbana Española (9 de mayo de 2021). Gobierno de España - Ministerio de Transportes, Movilidad y Agenda Urbana. https://www.aue.gob.es/agenda-urbana-espanola

Centro de Estudios y Experimentación de Obras Públicas, CEDEX. (2020). EVALUACIÓN DE RECURSOS HÍDRICOS EN RÉGIMEN NATURAL EN ESPAÑA (1940/41 -2017/18). Ministerio de Fomento, Ministerio para la Transición Ecológica. Madrid, España: Gobierno de España.

Clément, G. (2008). El Jardín en movimiento. Barcelona: GG.

Clément, G. (2018). Manifiesto del tercer paisaje. Barcelona: GG.

Costa, J.M., Lombó F. y Ferrero, F. (2021). Estudio del nivel de salubridad de las aguas continentales y litorales de Gijón (anualidad 2020). Informe para el Ayuntamiento de Gijón. Universidad de Oviedo.

Ecologistas en Acción (2020). Plan de naturalización y restauración ambiental del río Piles a su paso por la ciudad de Xixón (Asturies). Informe para el Ayuntamiento de Gijón.

El Pacto Verde Europeo (9 de mayo de 2021). Web oficial de la Unión Europea. https://ec.europa.eu/info/strategy/priorities-2019-2024/european-green-deal_es

Estrategia de la UE sobre la biodiversidad hasta 2020: nuestro seguro de vida y capital natural (9 de mayo de 2021). Comunicación de la Comisión al Parlamento Europeo, al Consejo, al Comité Económico y Social Europeo y al Comité de las Regiones. https://eur-lex.europa.eu/legal-content/ES/TXT/PDF/?uri=CELEX:52011DC0244\&from=ES

García, E. (2018). La transición ecológica: definición y trayectorias complejas. Rev. Ambienta 125, pp. 86-100. 
García de Jalón, D. y González del Tánago M. (2021). Diagnóstico ambiental y propuestas de actuación para la rehabilitación y/o renaturalización del curso bajo de los ríos Piles y Peña Francia en el Concejo de Gijón (Asturias). Informe para el Ayuntamiento de Gijón. Universidad Politécnica de Madrid.

Pellicer, F. (2002). Ordenación paisajística de espacios fluviales en ciudades mediterráneas. Paisaje y ordenación del territorio, pp. 283-295. Sevilla: Fundación Duques de Soria y Consejería de Obras Públicas y Transportes, Junta de Andalucía.

Pellicer, F. (2015). La recuperación de las riberas del Ebro en Zaragoza. Un efecto perdurable del evento efímero Expo 2008. En De la Riva, J., Ibarra, P., Montorio, R., Rodrigues, M. (Eds.) Análisis espacial y representación geográfica: innovación y aplicación, pp. 353-362. Zaragoza: Universidad de Zaragoza-AGE.

Pellicer, F. y Sopena, M.P. (2019). Grandes eventos, huellas del futuro. Las riberas del Ebro y Expo Zaragoza 2008. ZARCH 13, pp. 62-75.

Pentia Ingenieros (2001). Proyecto de modificación de aprovechamiento deportivo de los cauces de los ríos Piles y Peñafrancia. T.M. de Gijón (Asturias). Memoria y Planos.

Pueyo, À., Climent, E., Ollero, A., Pellicer, F., Peña Monné, J.L. y Sebastián, M. (2017). L’interaction de Saragosse et ses cours d eau: évolution, conflits et perspectives. M.Sud-Ouest Européen. Revue Géographique des Pyrénées et du Sud-Ouest, 44. Toulouse: Presses Universitaires du Mirail.

RGCC (Real Grupo de Cultura Covadonga) (2020 a). Análisis del Informe presentado por la Concejalía de Medio Ambiente sobre el río Piles. Informe de la Universidad de Zaragoza para el RGCC. Coord Pellicer, F., 35.

RGCC (Real Grupo de Cultura Covadonga) (2020 b). Anillo navegable de Gijón. Medidas de conservación y gestión para una instalación deportiva y saludable, atractiva y sostenible. Informe de la Universidad de Zaragoza para el RGCC, Coord Pellicer, F., 118.

Serrano-Notivoli, R., Beguería, S., Saz, M.Á., Longares, L.A. and de Luis, M.: SPREAD: a high-resolution daily gridded precipitation dataset for Spain - an extreme events frequency and intensity overview, Earth Syst. Sci. Data, 9, pp. 721-738, https://doi.org/10.5194/essd-9-721-2017, 2017.

UVANT Ingenieros (2020). Evaluación del estado hidrobiológico del río Piles en su tramo urbano y propuesta de medidas de gestión. Informe Técnico para el Ayuntamiento de Gijón. 